\title{
Efficient waste Gallus domesticus shell derived calcium-based catalyst for biodiesel production
}

\begin{abstract}
In this study, waste shells derived calcium-based catalysts were synthesized via wetimpregnation process in the presence of Mo-Zr mixed salt. The synthesized catalysts were characterized using $\mathrm{CO}_{2}$-TPD, XRD, BET surface measurement, SEM and EDX spectrometry, respectively. This heterogeneous catalyst was used to synthesize biodiesel via transesterification of waste cooking palm oil (WCPO) to fatty acid methyl ester in the presence of methanol. The catalyst demonstrated a superior catalytic performance in transesterification reaction, yielded $90.1 \%$ in $3 \mathrm{~h}$. Reusability of this waste shell derived catalyst was examined and results showed that the prepared catalysts are able to be reused up to 3 times with yield of more than $70 \%$ after the third cycles. Therefore, this new modified calcium-based catalyst exhibited outstanding activity and durability in the synthesis of biodiesel. The as-synthesized catalyst is recyclable and reusable, which successfully reduces the biodiesel production cost.
\end{abstract}

Keyword: Biodiesel; Transesterification; High FFA waste cooking oil; Gallus domestic; High basicity 